\title{
Satellite Remote Sensing Data Analysis for Flood Damaged Zoning with GIS for Flood Management
}

\author{
Md. Monirul ISLAM ${ }^{1}$ and Kimiteru SADO ${ }^{2}$ \\ ${ }^{1}$ Student Member of JSCE, PhD. Student, Dept. of Civil Engineering, Kitami Institute of Technology (165 Koen- \\ cho, Kitami 090-8507, Japan) \\ ${ }^{2}$ Fellow of JSCE, Dr. of Eng., Professor, Dept. of Civil Engineering, Kitami Institute of Technology (165 Koen-cho, \\ Kitami 090-8507, Japan)
}

\begin{abstract}
Flood frequency and flood water depth were estimated using satellite remote sensing data for the development of flood hazard map and flood risk zoning map. Physiographic divisions, geological divisions, administrative districts, road, rail and drainage network digital data were used through GIS approach. Flood damaged area for each physiographic division, geologic division and administrative district were estimated. Finally, the most safe flood hazard map for flood countermeasure was constructed by considering interact effect of flood water depth and flood frequency simultaneously. Flood risk zoning map for each administrative district was developed, which provides the information about the development and preparedness of the administrative districts, road and rails, etc. on the priority basis against the flood damages.
\end{abstract}

Key words: NOAA AVHRR data, hazard rank, flood hazard map, administrative district, physiographic division

\section{INTRODUCTION}

Floods have an impact on human society of Bangladesh. High magnitude floods occur on a regular basis in the three rivers basin of the Ganges, Brahmaputra and Meghna rivers in Bangladesh and out side of the Bangladesh in India and Nepal, because of the passages of depression and cyclone storm during the monsoon ${ }^{1)}$. The 1988 flood of Bangladesh which set hundred years record was the most devastating environmental hazard in the memorable history of Bangladesh. Therefore, the study focuses on that historical flood of 1988 .

The Brahmaputra, Ganges and Jamuna, three mighty rivers enter in Bangladesh from India through the north, north-west and north-east side of the country, respectively. The unprecedented flood of 1988 was caused by an unusual synchronization of the peak flood flow of the Ganges, Brahmaputra and Meghna $^{2)}$ which flooded more than fifty percent of the area of Bangladesh ${ }^{3}$. Flood hazard maps for the historical events are essential for the development of an effective flood management system. We developed two flood hazard maps by using NOAA AVHRR data with GIS for the event of 1988, considering flood frequency and flood water depth independently as a hydraulic factor to describe flood damage ${ }^{3), 77}$. GIS technology has been widely used in supporting surface water modeling and flood hazard exposure $^{5), 6), 7), 8)}$. However, in this study we employed the flood water depth and flood frequency simultaneously for the development of new flood hazard map. The purpose of this paper is to illustrate the development of flood hazard map, which is enhanced by GIS technology using NOAA AVHRR data. Hazard assessment focuses on the hazard ranks from normal to severe possessed by the 1988 flood event. After the identification of flood hazard ranks, formulation of the risk areas for each administrative district was performed.

\section{ESTIMATION OF FLOODED AREA}

\section{(1) Preparation of data}

Flood frequency and flood depth were calculated using the NOAA AVHRR images of Sep. 18, Sep. 24 and Oct. 8, 1988. Physiographic divisions, geological divisions, administrative districts, elevation height, drainage network, road and rail network data were related through a common coordinate system those can be displayed graphically on computer screen with NOAA AVHRR images. Land cover classification was performed by using the dry season image of Jan. 20, 1988.

\section{(2) Flood damage analyses}

Flood damaged areas were analyzed independently for physiographic divisions, geologic divisions and 
administrative districts by ISODATA clustering of unsupervised classification. ISODATA clustering is an iterative non-hierarchical clustering which uses minimum spectral distance to assign a cluster for each candidate pixel.

Bangladesh mainly divides into five physiographic divisions and then each main division divides into subdivisions. Highly flood affected divisions for 1988 flood are inundated eastern Barind Tract (99\%), western Jamuna floodplain (97\%) and northern Ganges floodplain (80\%) of north Bengal regions, eastern Jamuna floodplain (99\%), Sylhet Mymenshing haor area (95\%), very old Brahmaputra floodplain $(79 \%)$ and Titas river valley $(79 \%)$ of north eastern regions, and south east Ganges floodplain (active) $(78 \%)$ of south western regions. Comparatively Chittagong regions and Tippera Comilla regions were less affected.

Bangladesh consist of nine geological divisions and each geological division is divided into several subdivisions. Highly flood affected divisions for 1988 flood are Deltaic sand (74\%) of Deltaic deposits, Marsh clay and peat $(77 \%)$, alluvial silt $(77 \%)$, alluvial silt and clay $(80 \%)$ of Alluvial deposits.

There are sixty four administrative districts in Bangladesh. Dhaka is the capital city of Bangladesh. Natural hazards such as cyclone with strong surges attack the southern districts of the country and much of the districts routinely flood during the summer monsoon season. Highly flood affected districts are Bramanbaria (93\%), Gopalganj (93\%), Serajganj (92\%), Kishoreganj (92\%), Rajbari $(90 \%)$ and Manikganj (90\%) which precede Faridpur $(89 \%)$, Madaripur (89\%), Jamalpur (87\%), Dhaka (87\%), Sunamganj (86\%), and Netrokona (81\%). Khagrachari and Bandarban districts are almost flood free areas because of high land hilly areas of east-southern parts of the country. Some of the westnorthern, east-northern and east-southern parts near the boarder are high elevated land and all others districts are normal cultivated low elevated land.

\section{CONSIDERATION OF FLOOD FREQUENCY AND DEPTH FOR FLOOD DAMAGE ANALYSES}

\section{(1) Analysis of flood frequency}

Flood affected frequency were estimated by using the images of Sep. 18, Sep. 24 and Oct. 8, 1988. The three hypotheses can be surmised for flooded and newly flooded areas on Sept. 18, Sept. 24 and Oct. 8, 1988. The hypotheses concerning the presence of water in the image taken on Sept. 24, but its absence on Sept. 18, are that either it rained again between Sept. 18 and 24, or that water came from the previously flooded areas and spread out over the new areas, or that both phenomena occurred simultaneously. The above hypotheses can be adopted for water presence in the image of Oct. 8 but absence on Sept. 24 or Sept. 18. The hypotheses regarding the presence of common water in the three images are that either flooded water did not drain or flooded again after recovering between the two intervals of the three images. Inundated water not appeared in any above mentioned three images was considered to be a non hazard area, the inundated area that appeared in a single image was considered to be a low hazard area, the common inundated area that appeared in two images was considered to be a medium hazard area and the common inundated area that appeared in all three images was considered to be a high hazard area. The damage ranking were decided as class 1 , class 2 , class 3 and class 4 for non hazard, low, medium and high hazard areas, respectively.

\section{(2). Analysis of flood depth}

Flood depth were classified as shallow, medium and deep by using maximum likelihood method of supervised land cover classification. Training areas for shallow, medium and deep flood depth were assigned on NOAA AVHRR images according to the differences of colors and gray scales for different depths, these differences were understood after superimposing the NOAA images onto digital elevation image of Bangladesh. It is very difficult to show shallow, medium, and deep depth numerically, but it may be possible for simultaneous ground truth data. Flood water depths were classified from the images of Sep. 8, Sep. 24 and Oct. 8, 1988 for 1988 flood. The priority was given for the highest degree of depth among the three class flood water depths for three images. If deep flood depth appeared in a single image then it was considered as deep depth, and if medium depth appeared in a single image for the area that were represented as shallow depth by other two images then it was considered as medium depth. The ranking for flood water depth were considered as class 1 , class 2 , class 3 and class 4 for no flooding, shallow, medium and deep depth, respectively. Furthermore, flood depth for 1995 flood was estimated by using only one image of Aug. 31, 1995, and ranking for flood depth were classified as above mentioned four classes.

In order to judge the classified results of water depth, the average albedo was evaluated. Table 1 
Table 1 Albedo for different depths of flood water

\begin{tabular}{|c|c|c|c|c|c|c|}
\cline { 2 - 7 } \multicolumn{1}{c|}{} & NOAA 10 (1988) & \multicolumn{4}{c|}{ Albedo (\%) } \\
\cline { 2 - 7 } \multicolumn{1}{c|}{} & S (\%) & I (\%) & No water & Shallow & Medium & Deep \\
\hline B_1 & 0.10588 & -3.52794 & 6.80 & 5.13 & 4.52 & 4.59 \\
\hline B_2 & 0.10607 & -3.47665 & 10.65 & 9.44 & 4.80 & 3.43 \\
\hline \multicolumn{3}{|c|}{ NOAA 14 (1995) } & \multicolumn{4}{c|}{ Albedo (\%) } \\
\hline B_1 & 0.11440 & -4.69040 & 12.12 & 10.81 & 7.75 & 8.05 \\
\hline B_2 & 0.14356 & -5.88596 & 19.78 & 15.26 & 9.41 & 4.45 \\
\hline
\end{tabular}

shows the average albedo for the different flood depth which were evaluated using the image of Sep. 18, 1988 and Aug. 31, 1995. Albedo can be estimated by

$$
A_{i}=S_{i} C_{i}+I_{i}
$$

where, $A, C, S$, and $I$ are albedo, DN value, slope and intercept for $i$ band. The values of slope and intercept are also shown in Table 1. Band 1 is visible and band 2 is near infrared zone, therefore these two bands are normally used to estimate albedo. The albedo for shallow water is higher than the albedo for medium and deep depth and the albedo for medium depth is higher than the albedo for deep depth except for Band_1 (they are nearly equal), which can be considered as showing high turbidity of deep water with large amount of discharge per unit width. Albedo is generally related to turbidity and water depth, but here we considered albedo results for water depth only, because normally deeper flood water contain more turbidity than shallower flood water due to high water velocity during the flood. The results of albedo show the good agreement with the effective absorption of submerged sunlight by suspended solids for different depth of water.

\section{FLOOD HAZARD ASSESSMENT}

\section{(1) Estimation of weighted score and hazard rank}

Hazard rank were decided on based on a weighted score for the physiographic, geological, land cover classification and elevation height data for each pixel of the land area of Bangladesh. A weighted score was estimated by

$$
\text { Weighted score }=0.0 \times \text { class } 1+1.0 \times \text { class } 2
$$

$+3.0 \times$ class $3+5.0 \times$ class 4

The acquired area percentage of each class number for the physiographic divisions (31 divisions), geological divisions (28 divisions), land cover classification (9 categories) and elevation (9 intervals) were estimated on the basis of flood frequency and flood depth which were considered as hydraulic factors. Only the estimated results of geological divisions for the flood water depth are shown in Table 2 with counted score. Points for each
Table 2 Flood hazard ranks for geological divisions calculated by using flood water depth

(ID 9, 18, 27 appeared in geological map but not exist in this

\begin{tabular}{|c|c|c|c|c|c|c|c|}
\hline ID & Class 1 & Class 2 & Class 3 & Class 4 & Score & Point & HR \\
\hline 1 & 54.17 & 17.87 & 18.88 & 9.08 & 119.89 & 35.87 & 2 \\
\hline 2 & 69.25 & 11.48 & 8.50 & 10.77 & 90.81 & 27.17 & 1 \\
\hline 3 & 52.08 & 15.89 & 15.51 & 16.52 & 145.02 & 43.39 & 2 \\
\hline 4 & 72.78 & 18.40 & 6.24 & 2.58 & 50.02 & 14.96 & 1 \\
\hline 5 & 49.68 & 17.92 & 19.83 & 12.57 & 140.27 & 41.97 & 2 \\
\hline 6 & 53.73 & 21.69 & 14.88 & 9.70 & 114.83 & 34.36 & 2 \\
\hline 7 & 15.70 & 19.20 & 28.71 & 36.39 & 287.26 & 85.95 & 3 \\
\hline 8 & 20.33 & 16.10 & 16.99 & 46.58 & 299.96 & 89.74 & 3 \\
\hline 9 & 0.00 & 0.00 & 0.00 & 0.00 & 0.00 & 0.00 & 1 \\
\hline 10 & 20.99 & 19.19 & 26.81 & 33.01 & 264.68 & 79.19 & 3 \\
\hline 11 & 19.03 & 18.20 & 25.51 & 37.26 & 281.02 & 84.08 & 3 \\
\hline 12 & 54.68 & 23.55 & 10.86 & 10.91 & 110.70 & 33.12 & 2 \\
\hline 13 & 87.96 & 8.00 & 2.65 & 1.40 & 22.93 & 6.86 & 1 \\
\hline 14 & 72.24 & 21.54 & 5.30 & 0.91 & 42.02 & 12.57 & 1 \\
\hline 15 & 86.67 & 12.63 & 0.64 & 0.06 & 14.83 & 4.44 & 1 \\
\hline 16 & 82.34 & 13.32 & 3.93 & 0.41 & 27.16 & 8.13 & 1 \\
\hline 17 & 64.13 & 21.71 & 9.15 & 5.02 & 74.23 & 22.21 & 1 \\
\hline 18 & 0.00 & 0.00 & 0.00 & 0.00 & 0.00 & 0.00 & 1 \\
\hline 19 & 53.85 & 16.17 & 26.84 & 3.15 & 112.41 & 33.63 & 2 \\
\hline 20 & 99.45 & 0.55 & 0.00 & 0.00 & 0.55 & 0.16 & 1 \\
\hline 21 & 70.73 & 17.31 & 11.32 & 0.64 & 54.49 & 16.30 & 1 \\
\hline 22 & 76.84 & 8.70 & 11.25 & 3.21 & 58.51 & 17.50 & 1 \\
\hline 23 & 100.00 & 0.00 & 0.00 & 0.00 & 0.00 & 0.00 & 1 \\
\hline 24 & 85.41 & 7.49 & 4.22 & 2.88 & 34.55 & 10.34 & 1 \\
\hline 25 & 89.76 & 6.72 & 2.82 & 0.70 & 18.69 & 5.59 & 1 \\
\hline 26 & 93.85 & 2.42 & 3.72 & 0.00 & 13.59 & 4.07 & 1 \\
\hline 27 & 0.00 & 0.00 & 0.00 & 0.00 & 0.00 & 0.00 & 1 \\
\hline 28 & 14.29 & 13.32 & 20.51 & 51.88 & 334.24 & 100.00 & 3 \\
\hline
\end{tabular}
table due to low resolution of NOAA data, $1.1 \times 1.1 \mathrm{~km}^{2}$ )

ID categories were estimated on the basis of linear interpolation between 0 to 100 . The points 0 and 100 corresponded to the lowest $(0)$ and highest score (334.24). In order to quantify the flood hazard, the three ranking were obtained from the point those were prepared by considering the interactive effects of the physiography, geology, land cover classification and elevation on the flood hazard assessment. Hazard ranks were fixed by the corresponding value of the point, 0 to 33 correspond to hazard rank 1, 33 to 66 for 2 and 66 to 100 for 3 so that hazard ranks were categorized from 1 to 3 . Flood hazard map which was created on the basis of flood frequency using land cover classification and

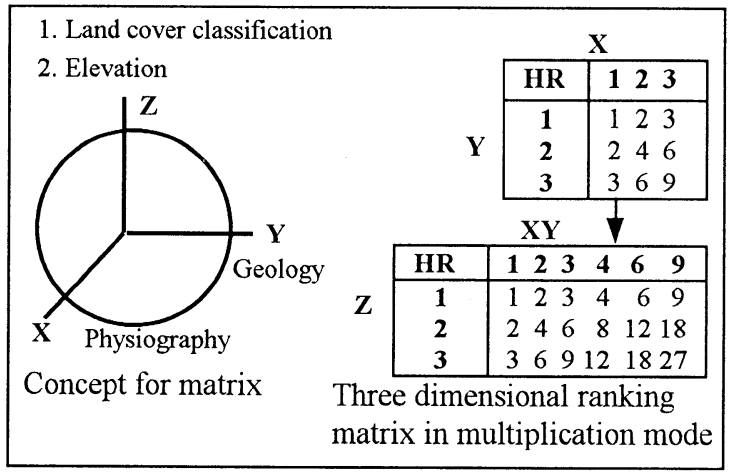

Fig. 1 Concept for ranking matrix in multiplication mode 


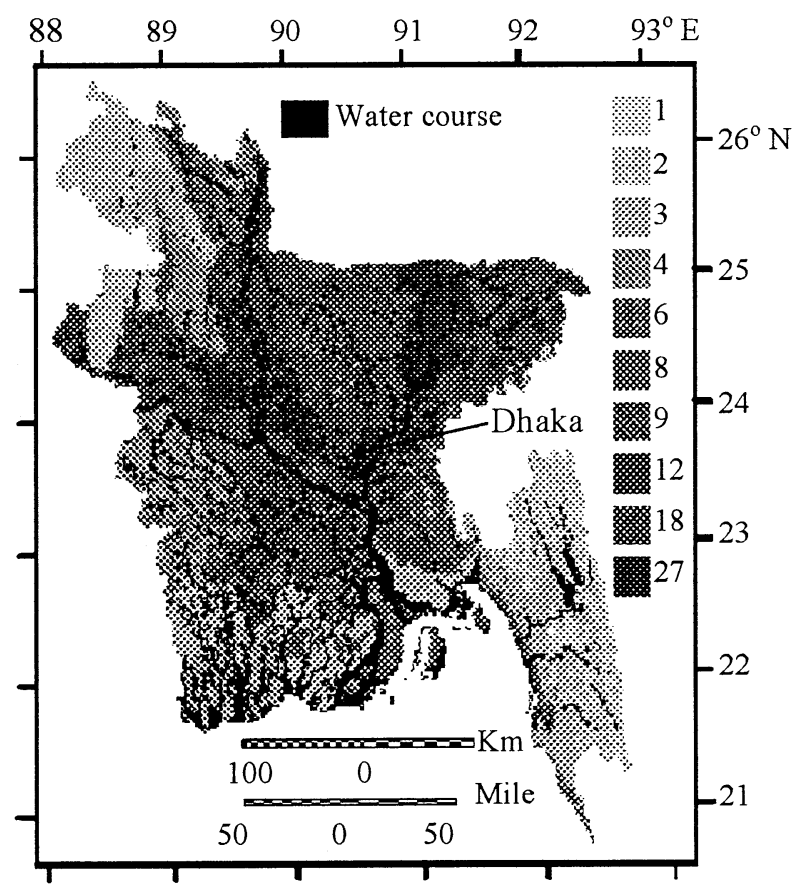

Fig. 2 Flood hazard map developed by considering the interact effect of flood frequency and flood depth with the combination of three thematic maps: physiographic division, geological division and land cover classification

elevation height data was shown in Hydrological Process $^{3)}$. All possible combinations of thematic maps were prepared for both flood frequency and flood depth, and combination by physiography, geology and land cover classification data shows the best combination for each of the flood hazard map performed for flood depth and flood frequency independently, those have congruence for $66 \%$ areas to each other ${ }^{4}$. The concepts of ranking matrix for three dimensional multiplication mode are shown in Fig. 1.

\section{(2) Considering the interact effect of flood depth and frequency for flood hazard map}

Two hazard maps were developed for flood depth and flood frequency respectively, by considering hazard rank from 1 to 27 , which were estimated by the ranking matrix of three dimensional multiplication mode for the combination of physiographic division, geological division and land cover classification. In these two hazard maps, $66 \%$ pixels show the same hazard ranks and $34 \%$ is different, because depth and frequency were considered independently. Therefore, a new hazard map was constructed by considering of higher hazard ranks. If one hazard map shows the higher rank than the other for a pixel, then the higher rank was assigned for that pixel. Physiographic and geological maps show different watercourses areas therefor the drainage networks was superimposed onto the new
Table 3 Hazard map results judging for another event of ' 95 flood (the column and row correspond to 1995 and 1988 flood, respectively)

\begin{tabular}{|c|rrrrrrrrrr|}
\hline $\mathrm{HR}$ & \multicolumn{1}{|c}{2} & \multicolumn{1}{c}{3} & \multicolumn{1}{c}{4} & \multicolumn{1}{c|}{8} & 9 & 12 & 18 & 27 \\
\hline 1 & $\mathbf{5 0 6 3}$ & 36 & 0 & 20 & 0 & 0 & 0 & 0 & 0 & 0 \\
2 & 4333 & $\mathbf{5 7 9 1}$ & 0 & 273 & 0 & 70 & 0 & 0 & 0 & 0 \\
3 & 0 & 3749 & $\mathbf{5 2 8 0}$ & 594 & 4194 & 433 & 0 & 1895 & 0 & 0 \\
4 & 7396 & 1437 & 2 & $\mathbf{3 0 1 3}$ & 12 & 123 & 0 & 0 & 0 & 0 \\
6 & 0 & 4914 & 3581 & 591 & $\mathbf{5 7 6 5}$ & 3 & 498 & 541 & 2 & 0 \\
8 & 1229 & 660 & 0 & 36 & 0 & $\mathbf{0}$ & 0 & 0 & 0 & 0 \\
9 & 0 & 0 & 0 & 723 & 1704 & 0 & $\mathbf{1 7 2 4}$ & 25 & 353 & 0 \\
12 & 0 & 6491 & 6962 & 1429 & 905 & 0 & 11 & $\mathbf{5 2}$ & 4 & 0 \\
18 & 0 & 0 & 0 & 6951 & 9881 & 274 & 4796 & 140 & $\mathbf{1 5 6 2}$ & 255 \\
27 & 0 & 0 & 0 & 0 & 0 & 1264 & 0 & 3259 & 2532 & $\mathbf{5 9 0 5}$ \\
\hline
\end{tabular}

developed hazard map. The final hazard map is shown in Fig. 2. This new hazard map will give more safety for the flood countermeasure compared with our previous developed hazard maps ${ }^{4}$, because the pixels belonging to higher degrees were increased due to the consideration of higher degrees of ranks.

\section{(3) Examine the flood hazard map for another event of flood}

In the year of 1995 and 1998 there were floods in Bangladesh, but those floods did not exceed the flood record of 1988. Flood hazard map constructed for the event of 1988 was examined for the event of 1995. Flood hazard map was developed for the event of 1995 by using flood depth only for the combination of three thematic maps: physiographic division, geological division and land cover classification. The comparison results are shown in Table 3. The elements of the column of the Table represent the number of pixels for the hazard ranks of 1995 flood while the rows of the Table represent the number of pixels for the hazard ranks of 1988 flood. If the elements of the flood hazard map of 1995 remain in and under the diagonal elements of the Table then the hazard map developed by using the flood event of 1988 is to be considered as a perfect one. Summation of diagonal elements is $28.77 \%$ and under diagonal elements is $63.38 \%$, diagonal elements and under diagonal elements, $92.15 \%$, are remained within the ranges of hazard ranks of the developed hazard map and the upper elements of diagonal, $7.85 \%$, are exceeded the hazard ranks of the developed hazard map. Although there is not hundred percent of congruence of the results, $92.15 \%$ percent were remained in the safe ranges of the developed hazard map for another event of 1995. Therefore the results of the developed map is to be considered as satisfactory. 


\section{FLOOD RISK ZONING FOR ADMINISTRATIVE DISTRICTS}

Bangladesh is divided into sixty four administrative districts. Flood risk zoning were developed for each administrative district by using the effect of flood hazard ranks of the pixels belonging to each administrative district. Mean hazard rank, $\overline{H R}$, for each administrative district was estimated for both flood frequency and flood depth independently by using

$$
\overline{H R}=\frac{\sum_{i} n_{i} r_{i}}{\sum_{i} n_{i}}
$$

where, $n_{i}$ is the number of pixels occupied by $i$ th hazard rank for each administrative district, $r_{i}$ is the $i$ th hazard rank value. Flood hazard rank was estimated for each pixel while flood risk rank was estimated for each administrative district. New hazard ranks were considered from 1 to 5 for both the flood frequency and the flood depth. The new hazard ranks from 1 to 5 were fixed by the corresponding value of the mean hazard rank, 1 for 1 to 5,2 for 5 to 10,3 for 10 to 15,4 for 15 to 20 and 5 for 20 to 25 . Higher rank means higher risk of the flood may occur for the administrative district. A flood risk zoning map that is shown in Fig. 3 was developed by the ranking matrix of two-dimensional multiplication mode for interact effect of flood frequency and flood depth, where risk ranks are 1,2 , $3,4,5,6,8,9,10,12,15,16,20$ and 25 . In this flood risk map, administrative districts were grouped as zone 1, 2, 3, 4 and 5 which correspond to lowest risk (risk rank 1, 2, 3, 4, 5), low risk (risk rank 6, 8, 9,10 ), medium risk (risk rank 12, 15), high risk (risk rank 16, 20) and very high risk (risk rank 25), respectively. The districts of Sunamganj, Kishoreganj, Serajganj, Manikganj and Narayanganj lie in very high risk area which covers $7.50 \%$ of total areas, then Sylhet, Hobiganj, Bramanbaria, Netrokhona, Norshingdi, Tangail, Natore, Pabna, Dhaka, Monshiganj and Gopalganj lie in high risk area which covers $16.34 \%$ of total areas of the country. $23.02 \%$ and $24.54 \%$ areas lie in medium and low risk and $28.60 \%$ areas are in lowest risk. By using MOS-1 MESSR data, authors showed that Dhaka City was highly affected by the flood of $1988^{9)}$. Furthermore, road network digital map was superimposed onto the risk zoning map of administrative districts to examine the probable road risk condition for flooding. Because the most damaging aspect of the flood has been destruction of

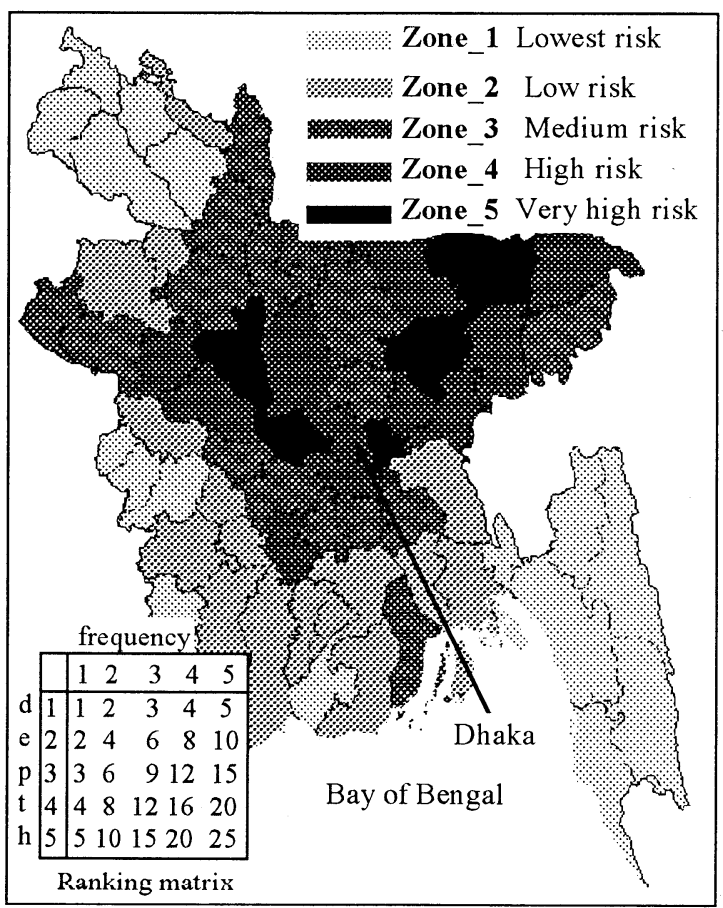

Fig. 3 Flood risk zoning map for administrative districts

people's means of livelihood due to interruption of transportation and communication, and submergence of houses, roads and rails, etc. The road communications from Dhaka city to other majors districts, those are falling in different risk zones are shown in Table 4. It seems that the major roads from Dhaka to north-east and Dhaka to north-west part of the country comparatively fall in higher degrees of risk zones. Similarly, communication from Dhaka to major districts by rails can be analyzed. Special attentions have to pay for the protection and the development of the roads and rails those were in high risk areas of flood. However, for the effective planning and necessary development of flood defenses and for the safety of the people those are living in higher risk areas and the administrative districts, roads and rails those are fall in high risk areas, a knowledge can be provided using this risk information. Flood forecasting, aid and necessary action for future event on priority basis can easily be taken by considering this flood risk zoning map.

\section{CONCLUSIONS}

The summarized conclusions are as follows:

(1) Flood hazard ranks were decided on the basis of interact effect of flood onto the physiographic, geological and land cover classification conditions of Bangladesh by using three dimensional multiplication mode of ranking matrix.

(2) Flood hazard assessment were undertaken by the consideration of interact effect of flood water 
Table 4 Risk zoning for highway from Dhaka to different part of the country

\begin{tabular}{|c|c|c|c|c|c|}
\hline Major Road & $\begin{array}{c}\text { Lowest risk } \\
\text { (Zone 1) }\end{array}$ & $\begin{array}{l}\text { Low risk } \\
\text { (Zone 2) }\end{array}$ & $\begin{array}{l}\text { Medium risk } \\
\text { (Zone 3) }\end{array}$ & $\begin{array}{l}\text { High risk } \\
\text { (Zone 4) }\end{array}$ & $\begin{array}{l}\text { Very high risk } \\
\text { (Zone 5) }\end{array}$ \\
\hline $\begin{array}{l}\text { Dhaka } \\
\text { to } \\
\text { South-East } \\
\text { part of the } \\
\text { country }\end{array}$ & $\begin{array}{c}\text { Chhagalnaiya to } \\
\text { Chittagong } \\
\text { Chittagong to Cox's Bazar } \\
\text { Chittagong to Hill Tract }\end{array}$ & $\begin{array}{l}\text { Daudkandi to Comilla } \\
\text { Comilla to Chhagalnaiya } \\
\text { Comilla to Mudaffarganj } \\
\text { Comilla to Lakshmipur, } \\
\text { Maijdi, Noakhali } \\
\text { Raiganj to Lakshmipur }\end{array}$ & $\begin{array}{l}\text { Meghnaghat to Daudkandi } \\
\text { Srimangal to Latu } \\
\text { Kulaura to Sherpur } \\
\text { Mudaffarganj to Chandpur } \\
\text { Chandpur to Raiganj }\end{array}$ & Dhaka to Meghna ghat & \\
\hline $\begin{array}{l}\text { Dhaka } \\
\text { to } \\
\text { North-East } \\
\text { part of the } \\
\text { country }\end{array}$ & & Comilla to Ramchandrapur & $\begin{array}{c}\text { Dhaka to Narshingdi } \\
\text { (part of Narshingdi dist.) } \\
\text { Narshingdi to Nandail } \\
\text { Kishoreganj to Bairab } \\
\text { Narshingdi to Bairab } \\
\text { Shyamganj to Mymensingh } \\
\text { Tongi to Halughat } \\
\text { Dhaka to Kaliakair } \\
\text { Jagannathganj to Jamalpur } \\
\text { Jamalpur to Mymensingh } \\
\text { Jamalpur to Bahadurabad } \\
\text { Jamalpur to Jhinaigati } \\
\text { Hobiganj to Srimangal } \\
\text { (part of Moulvi bazar dist.) }\end{array}$ & $\begin{array}{l}\text { Dhaka to Narshingdi } \\
\text { (part of Dhaka dist.) } \\
\text { Nandail to Netrokona } \\
\text { Netrokona to Shyamganj } \\
\text { Dhaka to Tongi } \\
\text { Kaliakair to Tangail } \\
\text { Tangail to Jagannathganj } \\
\text { Tangail to Char Gabsara } \\
\text { Ramchandrapur to Hobiganj } \\
\text { Hobiganj to Srimangal } \\
\text { (part of Hobiganj dist.) } \\
\text { Narshingdi to Shaistaganj } \\
\text { Shaistagang to Srimangal } \\
\text { (part of Habiganj dist.) } \\
\text { Srimangal to Sylhet }\end{array}$ & $\begin{array}{c}\text { Lamagazi } \\
\text { to } \\
\text { Sunamganj } \\
\text { Shaistagang } \\
\text { to Srimangal } \\
\text { (part of } \\
\text { Moulvibazar dist.) }\end{array}$ \\
\hline $\begin{array}{l}\text { Dhaka } \\
\text { to } \\
\text { North-West } \\
\text { part of the } \\
\text { country }\end{array}$ & $\begin{array}{l}\text { Gaibanda to Chilhati } \\
\text { Rangpur to Panchagram }\end{array}$ & & $\begin{array}{l}\text { Raiganj to Bogra } \\
\text { Nandigram to Bogra } \\
\text { Bogra to Rangpur } \\
\text { Nator to Rajshahi } \\
\text { Rajshahi to Rohanpur } \\
\text { Rajshahi to Nawabganj }\end{array}$ & $\begin{array}{l}\text { Dhaka to Manikganj } \\
\text { (part of Dhaka district) } \\
\text { Nagarbari to Kashinathpur } \\
\text { Kashinathpur to Bagabari } \\
\text { Kashinathpur to Ishurdi } \\
\text { Ishurdi to Nandigram }\end{array}$ & $\begin{array}{c}\text { Dhaka to } \\
\text { Manikganj } \\
\text { (part of } \\
\text { Manikganj dist.) } \\
\text { Manikganj to } \\
\text { Aricha, } \\
\text { Bagabari to Raiganj }\end{array}$ \\
\hline $\begin{array}{l}\text { Dhaka } \\
\text { to } \\
\text { South-West } \\
\text { part of the } \\
\text { country }\end{array}$ & $\begin{array}{l}\text { Patuakhali to Barguna } \\
\text { Jhenaidah to Meherpur } \\
\text { Kalaroa to Kaliganj }\end{array}$ & $\begin{array}{l}\text { Bhatiapara to Jessore } \\
\text { Char Magura to Gournadi } \\
\text { Gournadi to Patuakhali } \\
\text { Kamarkhali ghat to } \\
\text { Jhenaidah } \\
\text { Meherpur to Kushtia } \\
\text { Magura to Jessore } \\
\text { Jessore to Benapol } \\
\text { Jessore to Khulna } \\
\text { Khulna to Barisal }\end{array}$ & $\begin{array}{l}\text { Bhagyakul to Bhatiapara } \\
\text { Faridpur to Bhanga } \\
\text { Char Magura to Gournadi } \\
\text { (part of Madaripur dist.) } \\
\text { Faridpur to Kamarkhali } \\
\text { ghat }\end{array}$ & $\begin{array}{c}\text { Dhaka to Bhagyakul } \\
\text { Bhanga to Char Magura }\end{array}$ & \\
\hline
\end{tabular}

depth and flood frequency simultaneously, those were estimated from NOAA AVHRR data.

(3) New flood hazard map was proposed using 1988 flood data and examined the result for another event of 1995 flood, which shows that the $92.15 \%$ congruence of the results.

(4) Flood risk zoning map was illustrated for the administrative districts of Bangladesh and study shows that the districts of Narayanganj, Manikganj, Sunamganj, Kishoreganj and Serajganj are laid in very high risk zone.

(5) Risk study for highway shows that major roads from Dhaka to north-east and Dhaka to north-west comparatively fall in higher degrees of risk zones.

Therefore, this type of study will provide helpful information about flood protection measure such as construction and development of infrastructure and preparedness of aid and relief operation for high risk areas during future event of flood.

\section{REFERENCES}

1) Bhattacharyya, N. N.: Floods of the Brahmaputra river in India. Water International, J. International Water Resources Association, 22(4), 222-229, 1997.
2) Rasid, H. \& Pramanik, M.: Visual interpretation of satellite imagery for monitoring floods in Bangladesh. $J$. of Environmental Management, 14(6), 815-821, 1990.

3) Islam, M. M. \& Sado, K.: Flood hazard assessment in Bangladesh using NOAA AVHRR data with geographical information system. Hydrological Process, 2000, Vol. 14, No. 5 (in press).

4) Islam, M. M. \& Sado, K.: Development of flood hazard map of Bangladesh using NOAA AVHRR image with the approach of geographical information system. J. of Hydrological Science, 1999 (submitted).

5) Boyle, S. J., Tsanis, I. K. \& Kanaroglou, P. S.: Developing geographic information system for land use impact assessment in flooding condition. J. of Water Resour. Plng. and Mgmt., ASCE, 124(2), 89-98, 1998.

6) Greene, R. G. \& Cruise, J. F.: Urban watershed modelling using geographic information system. $J$. of Water Resour. Plng. and Mgmt., ASCE, 121(4), 318-325, 1995.

7) Ross, M. A., \& Tara, P. D.: Integrated hydrologic modeling with geographic information system. $J$. of Water Resour. Plng. and Mgmt., ASCE, 119(2), 129-140, 1993.

8). Schultz, G. A.: Meso-scale modelling of runoff and water balance using remote sensing and other GIS data. $J$. of Hydr. Scienc. Journal-des Scienc. Hydrologiques, 39(2), 121-141, 1994.

9) Sado, K. \& Islam, M. M.: Satellite remote sensing data analysis for flooded area and weather study: case study of Dhaka city, Bangladesh. Annual J. of Hydraulic Engineering, JSCE, 41, 945-950, 1997. 